\title{
Designing an Optimum Fiscal Policy for Tobacco to Maximise the Tax Revenue, Social Savings and the Net Monetary Benefits in Sri Lanka
}

\author{
Sathira Kasun Perera ${ }^{1^{*}(\mathbb{1}}$, Bharat Phani Vaikuntam ${ }^{1,2}$, Denny John ${ }^{3,4}{ }^{\circledR}$, Buddhika Senanayake $^{5^{\circledR}}$
}

\begin{abstract}
Background: Fiscal policy targeting tobacco control is identified as the most effective strategy for rapid control of tobacco use. An optimum fiscal policy to estimate the percentage taxation that will maximise the government tax revenue, social savings and the net monetary benefit has not been empirically designed before in Sri Lanka.

Methods: A model was developed using Microsoft Excel 2016, utilizing up-to-date published evidence on the cigarette sales, current fiscal policy, social cost of tobacco use, consumer response and the price elasticity of cigarettes. Univariate estimates on the expected revenue from tobacco tax, average annual social savings and the net monetary benefit were predicted for different levels of tobacco taxation. A deterministic sensitivity analysis was performed covering all possibilities. The percentage taxation maximizing the government tax revenue and the net monetary benefit were identified.

Results: It was estimated that a further $30 \%$ tax increase from the 2019 baseline will generate approximately LKR 3544 million per year of additional tax revenue for the government while saving LKR 28069 million per annum as social savings. A fiscal elevation of $50 \%$ will produce identical annual tax revenue to that of 2018 , while securing a social saving of more than LKR 47600 million per annum. The maximum net monetary benefit is achievable at an overnight tax increase of $90 \%$ from the baseline, however with a short-term compromise in tax revenue.

Conclusion: The well-defined thresholds take tobacco taxation advocacy in Sri Lanka a step forward and will assist the government in taking an informed decision on its fiscal policy for cigarettes.

Keywords: Optimum Tobacco Taxation, Tobacco Tax Sri Lanka, Tobacco Control

Copyright: () 2020 The Author(s); Published by Kerman University of Medical Sciences. This is an open-access article distributed under the terms of the Creative Commons Attribution License (http://creativecommons.org/ licenses/by/4.0), which permits unrestricted use, distribution, and reproduction in any medium, provided the original work is properly cited.

Citation: Perera SK, Vaikuntam BP, John D, Senanayake B. Designing an optimum fiscal policy for tobacco to maximise the tax revenue, social savings and the net monetary benefits in Sri Lanka. Int J Health Policy Manag. 2020;9(6):250-256. doi:10.15171/ijhpm.2019.114
\end{abstract}

Article History:

Received: 27 August 2018

Accepted: 9 November 2019

ePublished: 1 December 2019
*Correspondence to:

Sathira Kasun Perera

Email:

sathira.perera@student.unsw.edu.au

\section{Key Messages}

Implications for policy makers

- It is estimated that the use of tobacco contributes to a significant amount of disease burden and social costs worldwide. Taxation has been shown one of the most effective tobacco control strategies helping to minimise the social cost due to tobacco use. An optimum fiscal policy estimating the percentage taxation that will maximise the government tax revenue, minimise the social costs and produce the maximum net monetary benefit has not been empirically designed before in Sri Lanka. This study predicts the tax revenue, social cost and the net monetary benefit at different levels of tobacco taxation in Sri Lanka, from a government perspective.

- The current advocacy on this is not based on such well-defined cut off values, making it difficult for the policy-makers to take an informed decision on the exact thresholds to use in developing the fiscal policy. Taking advocacy on tobacco control in Sri Lanka to a higher level, the three well-defined thresholds identified for maximising tax revenue, remaining revenue neutral while maximising the social cost savings and for maximizing the net monetary benefit will assist the policy-makers to take an informed decision on its fiscal policy for cigarettes.

Implications for the public

This study may assist the public in re-establishing their perception that there is a social cost of smoking at population level and the resultant economic impact is not recoverable by the temporary gains in tax revenue. The public will also gain a better level of understanding on the need to implement taxation policies as a method of controlling tobacco use and the long-term benefits of such fiscal intervention. This will further strengthen and support the public perception in favour of raising tobacco taxes to empirically estimated cut-off values. The myth that "smoking a cigarette contributes to the tax revenue and indirectly to the economic development," could be effectively nullified by understanding the core concepts of this modelling exercise in terms of negative net monetary benefit of increasing tobacco consumption. 


\section{Background}

The use of tobacco products has been estimated to be the leading cause of burden of disease in developed countries. It is also the single most preventable cause of morbidity and mortality around the world, accounting for nearly $12 \%$ of all deaths among adults over 30 years of age. ${ }^{1}$ The health, social, and economic impact of smoking is substantial. The effect of productivity loss due to tobacco use is also significant as the tobacco mortality peaks in later adulthood owing to its associations with many chronic non-communicable diseases. ${ }^{2}$

The situation in lower-middle-income countries including Sri Lanka is no different. The economic burden of tobacco use was estimated to be above LKR 89 billion per year from a health systems perspective, including the household direct and indirect costs. ${ }^{3}$ If Sri Lanka can target to reduce tobacco consumption, it is possible to recover a significant amount of financial resources spent on managing complications of tobacco use.

The demand of tobacco, like any other usual 'economic good' responds to price changes relative to the price of other products, real income changes, and changes in tastes and preferences. ${ }^{4,5}$ Fiscal policies targeting tobacco control has by far been the most effective strategy for rapid cut-off of smoking rates. Tobacco specific excise taxes are more effective in achieving health gains compared to ad valorem taxes which are difficult to implement in complex tax systems. ${ }^{6}$ Evidence from both high and middle/lower income countries suggest that large increases in tobacco specific excise taxes to have a substantial and rapid effect on consumption. ${ }^{7}$ In many highincome countries, specific excise taxes account for around $50 \%-60 \%$ of the retail price, compared to $35 \%$ to $40 \%$ in middle/lower income countries. ${ }^{8,9}$ So, doubling the excise taxes can double the retail price in higher income countries, it would require even-higher tax increases to achieve a similar effect. Tax by weight is recommended as companies try to work around the tax if by per cigarette by increasing size of cigarette to king or super king. ${ }^{10}$ Careful regulation of imports and imposing excise duties help to control illegal imports of tobacco. The relative prices of alternative forms of tobacco and their relative health impacts significantly impact the overall tobacco consumption and health burden. Equivalent taxation of alternative products is required for the taxation to be effective in reducing health burden. ${ }^{6}$

Even though other control strategies like price promotion restrictions, minimum price laws and health promotion initiatives have proven effectiveness, ${ }^{11}$ fiscal interventions are easy to implement with an overnight impact on tobacco use, improving population health and reducing smoking related health risks. The World Health Organization Framework Convention on Tobacco Control identifies price and taxationbased interventions as a major tobacco control strategy. ${ }^{12,13}$ Fiscal interventions in many different countries across the globe have been observed to be highly effective in reducing consumption ${ }^{14,15}$ including in settings with similar socioeconomic backgrounds to Sri Lanka. ${ }^{16}$ Simulations elsewhere have shown that even in a conservative scenario, increasing the price by $100 \%$ using fiscal measures maximizes revenues and reduce cigarette consumption. ${ }^{17}$
Currently, Sri Lankan fiscal policy on tobacco follows a lump sum tax imposed on the number of cigarettes sold. It is noted that there have been recent tax increases with evidence of reduction of tobacco consumption in the country. ${ }^{18} \mathrm{~A}$ tax is levied and paid on every cigarette manufactured in Sri Lanka. The rate is defined by the minister of finance, published in the Gazette. The tobacco tax is payable by the industry and the tax is computed based on the number of cigarettes manufactured at, and removed from, the factory at which such manufacture is carried on. Thus, the total amount of the tax payable is calculated on the total quantity of cigarettes removed from a factory.

The government tax revenue from tobacco sales in year 2017 was about LKR 88 billion. ${ }^{18}$ It is understood that even though there is a heavy social cost of tobacco use, being a third world country, the government depends on tax revenue to manage annual government expenditure. Thus, it is required to evaluate in economic terms, whether the current percentage taxation on tobacco products is the optimum rate that could maximize government excise tax revenue, while minimising the tobacco consumption and the social cost of tobacco use.

The objective of this analysis was to provide an empirically designed estimate of the optimum percentage of taxation that may be applied on tobacco products and to estimate the potential economic benefits of such an effective fiscal policy targeting tobacco control in Sri Lanka.

\section{Methods}

A model was developed using Microsoft Excel 2016, utilizing up-to-date published evidence on the current status of cigarette sales in Sri Lanka, current fiscal policy on tobacco, social cost of tobacco use, effectiveness of tobacco control strategies, product substitution data, consumer response to cigarette price increase, and the price elasticity data of cigarettes (see Supplementary file 1).

Data Inputs

Cigarette price for year 2019 was obtained from surveying 20 retail shops in Sri Lanka, where a uniform price was observed in all outlets. The information with regard to tobacco sales was obtained from the annual report of the Ceylon Tobacco Company ${ }^{19}$ which holds the monopoly of tobacco production and sales in Sri Lanka. Information on the current fiscal policy, fiscal limits on various tobacco products and the tax revenue was obtained from the Fiscal Management Report of the Ministry of Finance, 2017, Sri Lanka. ${ }^{18}$ Price elasticity of demand was obtained from studies conducted around the world. ${ }^{20,21}$ Social cost of tobacco use has been extensively quantified in a recent study conducted in Sri Lanka, based on the dose response data and tobacco attributable fraction of different tobacco related diseases. The direct and indirect costs of managing health conditions due to tobacco use including the health system costs, out of pocket expenditure and productivity loss has been quantified comprehensively in this recent estimation of tobacco related social costs conducted in Sri Lanka. Thus the annual social cost due to tobacco consumption estimated in this study was used as an input to the model. ${ }^{3}$ The data inputs and the range of values 
Table 1. Data Inputs and Values Used in the Model Building Process

\begin{tabular}{|c|c|c|}
\hline Data Input & Range of Values Used & Reference \\
\hline \multirow{4}{*}{ Annual tobacco sales volume of individual tobacco products } & Brand 1: 3154 million sticks & \multirow{4}{*}{19} \\
\hline & Brand 2: 304 million sticks & \\
\hline & Brand 3: 228 million sticks & \\
\hline & Brand 4: 114 million sticks & \\
\hline \multirow{3}{*}{ Market share of individual tobacco products } & Brand 1: $83 \%$ & \multirow{3}{*}{19} \\
\hline & Brand 2: $8 \%$ & \\
\hline & Brand 4: 3\% & \\
\hline \multirow{5}{*}{ Price elasticity of demand of cigarettes } & LMIC: -0.53 & 22 \\
\hline & Population (LMIC): -0.74 & 20 \\
\hline & India: -0.65 & 16 \\
\hline & Youth (conditional): -2.11 & 20 \\
\hline & Adult: -1.17 & 21 \\
\hline \multirow{3}{*}{ Price of different brands of cigarettes currently sold } & Brand 1: LKR 65 & \multirow{3}{*}{$\begin{array}{l}\text { Primary market data } \\
\text { (November 2019) }\end{array}$} \\
\hline & Brand 3: LKR 55 & \\
\hline & Brand 4: LKR 70 & \\
\hline Government revenue from tobacco taxation & LKR 87400 million & 18,19 \\
\hline Social cost of tobacco use in Sri Lanka (converted to 2019 value) & LKR 110333 million & 3 \\
\hline Industry claimed substitution factor for cheap alternatives (Beedi) - per $10 \%$ in taxes & $1 \%-2 \%$ & 19 \\
\hline Discount factor & $0.03-0.06$ & 23 \\
\hline
\end{tabular}

Abbreviation: LMIC, low- and middle-income country.

used in the model are summarized in Table 1.

\section{Model Building and Outcomes}

Univariate estimates on the expected revenue from tobacco tax, average annual social cost savings and the net monetary benefits were derived for different predicted levels of tobacco taxation. Minimum and maximum values for all estimates were calculated in a deterministic sensitivity analysis covering all possibilities, to represent the uncertainty around the estimates.

Using economic evidence on fiscal policy and price elasticity, the suggested fiscal policy was developed, targeting tobacco control while optimizing government revenue. A graded analysis on the economic impact of the suggested fiscal policy was performed to inform all possible policy options for the government of Sri Lanka.

The graded increase of percentage taxation was applied on the current price of the commonly used tobacco products which govern more than $90 \%$ of the market share. A new range of price was estimated for each individual product.

Based on the price elasticity of demand for cigarettes, new demand curves for each product were derived. The changes to the quantity of sales were estimated for each product and the new sales volumes calculated. Predicted government tax revenue at each different level of taxation was calculated using the unit tax and the predicted quantity of sales at each level of taxation. The percentage taxation that will maximize the government tax revenue was identified. This was defined as the "tax revenue maximising cut off" for optimum tobacco taxation in Sri Lanka.

Social cost savings due to reducing tobacco consumption at each level of taxation was predicted using recently published Sri Lankan data on the social cost of tobacco use based on the dose response data and tobacco attributable fraction of different tobacco related diseases.

The level of taxation at which the government tax revenue remains unchanged from the baseline 2017 value, while producing greater social savings was identified. This was defined as the "revenue neutral cut off" from a government perspective.

The cost saving due to averted social cost was added to the annual increment of government tax revenue to calculate the net monetary benefit of implementation of the suggested fiscal policy at different levels of taxation from a government perspective. The percentage taxation that will maximize the net monetary benefit was identified. This was defined as the "net monetary benefit maximising cut off" for optimum tobacco taxation in Sri Lanka.

All calculations were based on the assumption that taxes are increased overnight from the baseline value up to the suggested new threshold. Tobacco industry's own claim about substitution to other alternative unregulated products was also in cooperated to improve acceptability of the results from an industry perspective.

A deterministic sensitivity analysis was performed to account for the uncertainty around the price elasticity of demand of cigarettes and the substitution factor.

\section{Results}

Table 2 depicts the model predicted tobacco sales volume, tax revenue, social savings and the net monetary benefit of increasing tobacco taxes at different percentages from the baseline tax.

The expected change in tax revenue, social cost and the predicted net monetary benefit over the range of fiscal inputs are depicted in Figure 1. The predictions for net monetary benefit at 30\%,50\% and $80 \%$ tax increases from baseline are depicted in Figure 2, assuming a delayed social benefit for 5 
Table 2. The Effect of Increasing Tobacco Taxation Expressed in Terms of Predicted Government Tax Revenue, Social Cost Savings and Net Monetary Benefit

\begin{tabular}{|c|c|c|c|c|}
\hline $\begin{array}{l}\text { Level of Taxation (Actual Price of the } 4 \text { Brands of } \\
\text { Cigarettes, in Order of Popularity LKR) }\end{array}$ & $\begin{array}{l}\text { Total Predicted Annual } \\
\text { Sales (Million Sticks) }\end{array}$ & $\begin{array}{l}\text { Predicted Annual Tax } \\
\text { Revenue (LKR Million) }\end{array}$ & $\begin{array}{c}\text { Predicted Annual } \\
\text { Social Savings (LKR } \\
\text { Million) }\end{array}$ & $\begin{array}{c}\text { Predicted Annual Net } \\
\text { Monetary Benefit (LKR } \\
\text { Million) }\end{array}$ \\
\hline Baseline $(65,20,55,70)$ & 3800 & 115810 & 0 & 0 \\
\hline $10 \%$ increase $(71.50,22,60.50,77)$ & 3492 & 116990 & 8474 & 9654 \\
\hline $20 \%$ increase $(78,24,66,84)$ & 3253 & 118899 & 18271 & 21361 \\
\hline $30 \%$ increase $(84.50,26,71.50,91)$ & 3015 & 119354 & 28069 & 31613 \\
\hline $40 \%$ increase $(91,28,77,98)$ & 2776 & 118354 & 37866 & 40410 \\
\hline $50 \%$ increase $(97.50,30,82.50,105)$ & 2537 & 115899 & 47664 & 47754 \\
\hline $60 \%$ increase $(104,32,88,112)$ & 2298 & 111991 & 57461 & 53642 \\
\hline $70 \%$ increase $(110.50,34,93.50,119)$ & 2059 & 106628 & 67259 & 58077 \\
\hline $80 \%$ increase $(118,36,99,126)$ & 1821 & 99810 & 77057 & 61057 \\
\hline $90 \%$ increase $(124.50,38,104.50,133)$ & 1582 & 91538 & 86854 & 62582 \\
\hline
\end{tabular}

years. It is evident that a $30 \%$ increase from baseline tax will maximize the government tobacco tax revenue while a $90 \%$ increase will maximize the net monetary benefits, assuming linear social savings from the origin. Thus, 30\% was defined as the "tax revenue maximising cut-off" while 90\% was considered the "net monetary benefit maximising cut-off."

As depicted by the tax benefit curve in Figure 1, at about $50 \%$ increase from the baseline, the government tax revenue again crosses the baseline, indicating that the government can stay revenue neutral at this level, while eliciting a significant social saving of more than LKR 40000 million per annum. Thus, $50 \%$ fiscal elevation was considered the "revenue neutral cut-off" of tobacco taxation.

The predicted net monetary benefit of the suggested fiscal changes is depicted at $30 \%, 50 \%$, and $90 \%$ fiscal elevations over a period of 10 years, assuming a 5-year latent period for appearance of social cost savings. It is evident that a $30 \%$ increase in tobacco taxation will optimise government tax revenue while a $90 \%$ increase will have a negative effect on tax revenue in the short run. However, following the latent period of 5 years, the $90 \%$ increase in taxes produces the highest net monetary benefit when the social cost savings start to accumulate. Thus, in the long run, the tax increases less than $90 \%$ will be suboptimal.

Table 3 depicts the results of the deterministic sensitivity analysis with the range of expected values for the increase in tax revenue, social cost savings and the net monetary benefit at suggested $30 \%$ and $90 \%$ cut off values for tobacco tax increase. The model outputs were sensitive to the price elasticity of demand of cigarettes. Thus, a wide range of relevant inputs

Predicted annual tax revenue, annual social savings and annual net monetary benefit of fiscal increments

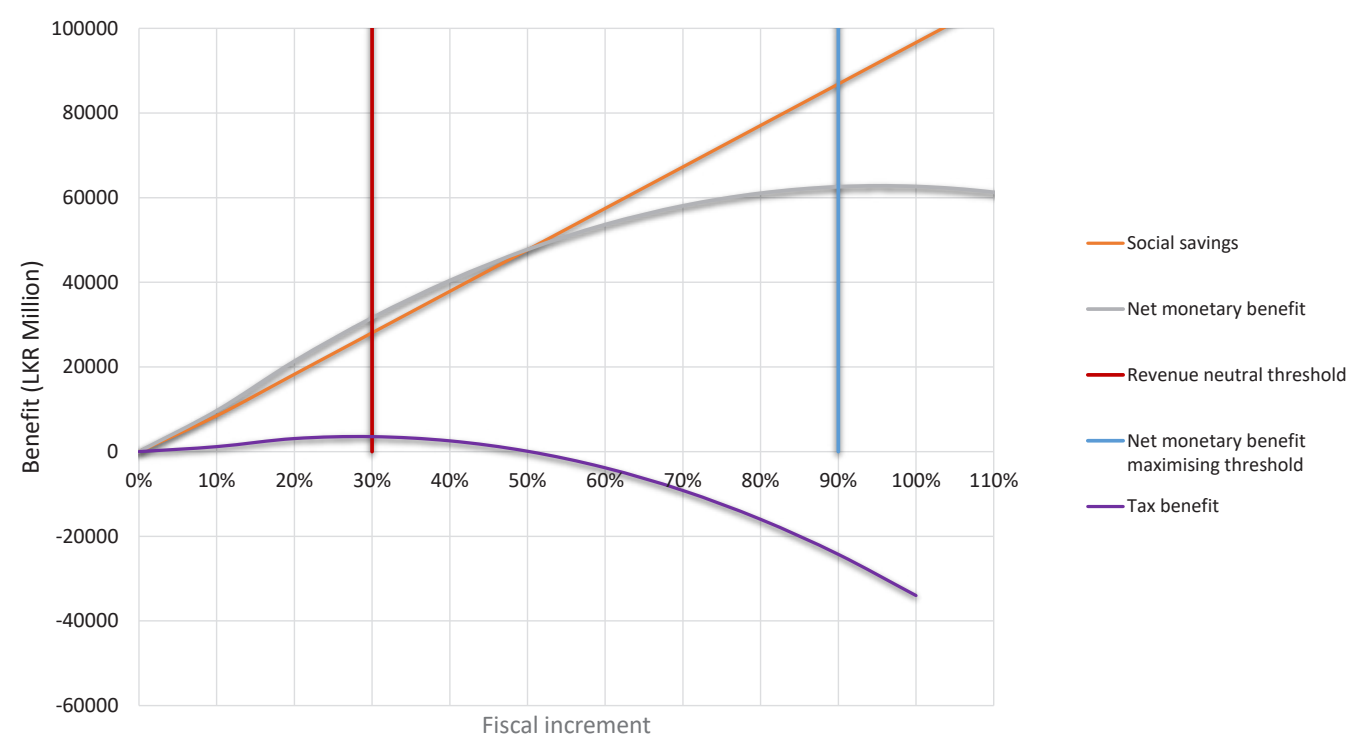

Figure 1. Predicting the Optimum Percentage of Taxation on a Cigarette Using the Tax Revenue, Social Cost Savings and net Monetary Benefit Predictions - Assuming Immediate Social Benefits. 


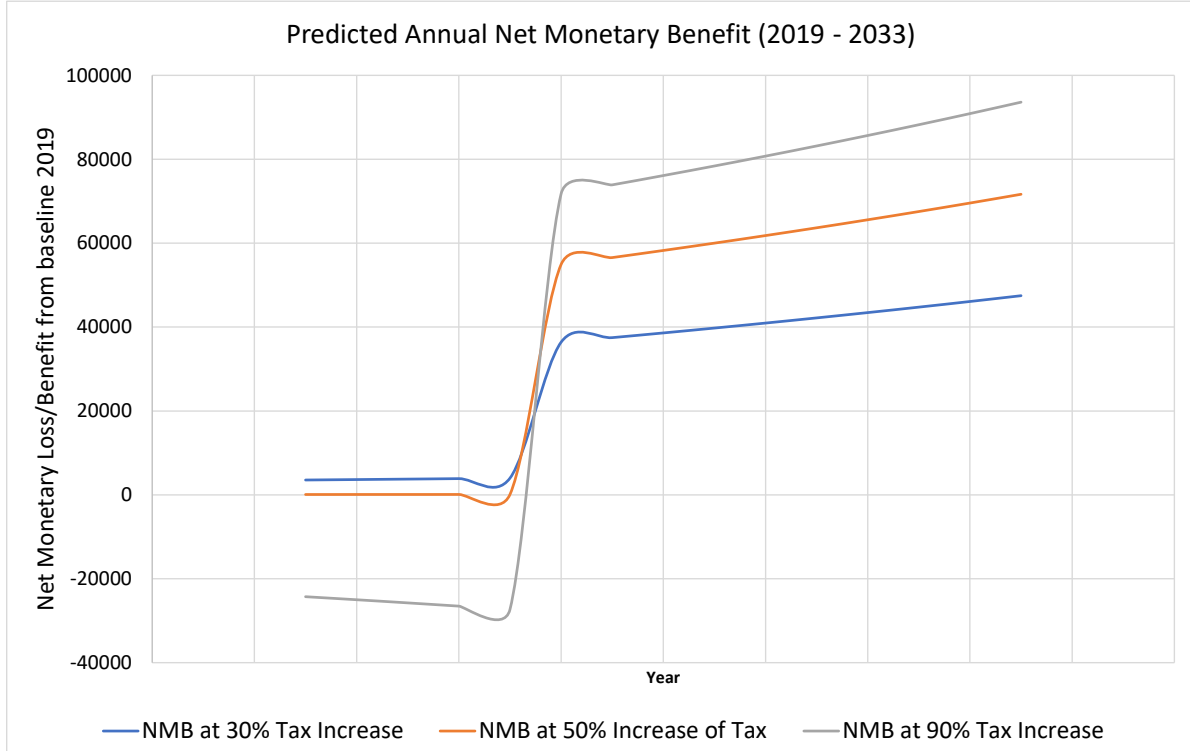

Figure 2. Predicting the NMB of Tobacco Tax Increase at 30\%, 50\%, and 80\% From the Baseline - Assuming Delayed Social Benefits for 5 Years. Abbreviation: NMB, net monetary benefit.

were used to increase the acceptability of results at different levels of price elasticity.

\section{Discussion}

It is estimated that a $30 \%$ tax increase (to tax revenue maximising cut-off) from the baseline level of tobacco taxation will generate approximately LKR 3544 million per year of additional tax revenue for the government of Sri Lanka while saving LKR 28069 million per annum as social cost due to reducing tobacco consumption. Thus, the net monetary benefit of increasing tobacco tax by $30 \%$ will exceed LKR 31613 million per year. Considering the evidence that price elasticity of demand for cigarettes is greater among the youth and among the low-income groups, the actual benefit in terms of social cost saving could be greater than predicted. ${ }^{24}$ Raising tobacco taxes can have income distributional effects with disproportionate burden on lower income individuals in the short run, but these tobacco control measures are progressive and lead to reduction of social inequality in the long run. ${ }^{25}$ Past experience in different parts of the world shows that even with lower price elasticities such as -0.24 , there could be greater fiscal gains with a considerable public health impact. ${ }^{26}$ Greater benefits have been demonstrated elsewhere. ${ }^{27-29}$ It has also been shown that greater tax hikes change the tobacco industry pricing strategy to increasing industry net-of-tax prices, as opposed to the strategy of shielding consumers in situations where there are smaller tax hikes. ${ }^{26}$

Gilmore et $\mathrm{al}^{10}$ found the pricing strategies of tobacco companies to be influential on the effectiveness of tobacco tax as the companies can potentially absorbing any tax increases for mid/ultra-low-price brands by over-shifting (increasing prices on top of tax) to premium brands in the United Kingdom. This could lead to bigger price gaps between premium and low-price brands, thereby enabling smokers to substitute to low-price brands. A similar effect has also been found by Nargis et al in Canada where a widened price differential between premium and discounted brands contributed to a higher share of discount brand cigarettes. ${ }^{30}$ Governments must monitor cigarette prices by price segment and consider industry pricing strategies in setting tobacco tax policies.

France and South Africa have halved the consumption in less than 15 years compared to nearly three decades time taken by the United States and the United Kingdom to halve the cigarette consumption. ${ }^{31}$ Between 1995-2005, France and South Africa introduced large tax increases annually resulting in tripling of inflation-adjusted cigarette prices, whilst doubling their inflation adjusted tobacco revenue despite

Table 3. Results of the Deterministic Sensitivity Analysis With the Predicted Annual Increase in Tax Revenue, Social Cost Savings and the Net Monetary Benefit at Suggested 30\% And 90\% Cut Off Values for Tobacco Tax Increase in Response to the Variability of Price Elasticity of Demand and Substitution Factor

\begin{tabular}{|c|c|c|c|c|c|c|}
\hline \multirow{2}{*}{ Input } & \multicolumn{2}{|c|}{$\begin{array}{l}\text { Predicted Gain in Tax } \\
\text { Revenue (LKR Mn) }\end{array}$} & \multicolumn{2}{|c|}{$\begin{array}{l}\text { Predicted Social Savings } \\
\text { (LKR Mn) }\end{array}$} & \multicolumn{2}{|c|}{$\begin{array}{l}\text { Predicted Net Monetary Benefit } \\
\text { (LKR Mn) }\end{array}$} \\
\hline & $\begin{array}{l}30 \% \text { Tax } \\
\text { Increase }\end{array}$ & $\begin{array}{l}\text { 90\% Tax } \\
\text { Increase }\end{array}$ & $\begin{array}{l}30 \% \text { Tax } \\
\text { Increase }\end{array}$ & $\begin{array}{l}90 \% \text { Tax } \\
\text { Increase }\end{array}$ & $\begin{array}{l}30 \% \text { Tax } \\
\text { Increase }\end{array}$ & $\begin{array}{l}90 \% \text { Tax } \\
\text { Increase }\end{array}$ \\
\hline $\begin{array}{l}\text { Base case analysis } \\
\text { Price elasticity }-0.74 \text {, substitution factor } 1 \%\end{array}$ & 3544 & -24272 & 28069 & 86854 & 31613 & 62582 \\
\hline Price elasticity of demand of cigarettes of -0.53 & 12850 & 16532 & 19728 & 61831 & 32578 & 78362 \\
\hline Price elasticity of demand of cigarettes of -0.65 & 7532 & -6785 & 24494 & 76130 & 32026 & 69345 \\
\hline Substitution factor of $2 \%$ & 7975 & -4842 & 26745 & 85530 & 34720 & 80688 \\
\hline
\end{tabular}


halving the cigarette consumption. ${ }^{32-34}$ However, the lack of sufficient price rises between 2005 and 2010 have led to an increase in prevalence of smoking in France demonstrates the significance of sustained efforts to achieve robust tobacco control.

It could be noticed that at the proposed tax revenue maximising level of taxation in Sri Lanka, the tobacco sales will drop by an estimated $26 \%$, shrinking the industry volume. The analysis of market trends on the response of the tobacco industry shows that in almost all scenarios, the industry diverts the tax increase to consumers, rather than absorbing it. The evidence also shows that the industry prefers to increase the price of cigarettes by a greater margin, to nullify the effect of reduced sales on the profit margin. Thus, it could be concluded that the proposed tax increase may not raise concerns for the viability of the industry, as often claimed by them.

It has also been shown that consumers are unlikely to substitute standard products of their choice, with substandard products like beedi. ${ }^{35}$ Even though, an assumption of nonsubstitution seems reasonable, a substitution factor of $1 \%$ per each $10 \%$ price increase on regulated tobacco products was considered for base-case analysis to allow for any possible margin of error. According to the tobacco industry's own claim, the rise in beedi consumption has been $24 \%$ over a period of 10 years, ${ }^{19}$ while the price of regulated tobacco increased by more than $250 \%$. Thus the assumption of $1 \%$ substitution to unregulated products per each $10 \%$ price increase on regulated tobacco, entertains the claim of the tobacco industry that the consumption of unregulated tobacco increases in response to tax hikes on regulated products. ${ }^{19}$ The price of the second most sold brand has a price of $20 \mathrm{LKR}$, while the top brand is $65 \mathrm{LKR}$. Since the great majority of the market is occupied by the premium brand, and the cheaper alternatives hold only a relatively small segment of the market, a significant trading down to cheaper brands is unlikely. However, a substitution factor of $2 \%$ for beedi was also considered in the sensitivity analysis to depict an extreme possibility, which also confirmed similar tax and social benefits. This effectively nullifies the claim of the industry that cigarette price increases lead to substantial loss of tax revenue to the government, while also depicting that the social savings also remain robust to the substitution factor.

It was also depicted that, at approximately 50\% (revenue neutral cut-off) of fiscal elevation from the baseline 2017 tax thresholds, the government can stay revenue neutral (raise same tax revenue as of year 2017), while achieving about $50 \%$ of the maximum possible social savings. Thus, one may argue that this is the most practical and effective cutoff a government can choose as it produces significant social benefits without any impact on the tax revenue.

It is noteworthy that the maximum net monetary benefit is achievable at an overnight tax increase of $90 \%$ from the baseline (net monetary benefit maximising cut-off), assuming a price elasticity of -0.74 . At the lower margin of the range of price elasticity used $(-0.52)$, the model predicted that there will still be a gain in tax revenue of LKR 18475 million.
It could be concluded that the government of Sri Lanka is currently operating at a sub-optimal level of tobacco tax percentage, generating loss of excise tax revenue and greater opportunity costs in socio-economic, health and quality of life perspectives. Thus, it is recommended that the government revises its fiscal policy on tobacco based on any of the above identified cut-offs.

It is entirely a policy decision, which cut-off the government wants to choose. To summarize, the "tax revenue maximising cut-off" of $30 \%$ increase of tobacco taxation will maximise and the government tax revenue, still offering significant social savings. The "revenue neutral cut-off" of $50 \%$ increase will allow the government to enjoy the same tax revenue as of 2017, while achieving greater social savings. The "net monetary benefit maximising cut-off” of 90\% increase will produce the optimum net monetary benefit for the country. The model predicted further that at the lower limits of price elasticity (-0.52), the government could expect to boost its excise tax revenue even at a percentage tax increase of $130 \%$.

At tax elevations grater than $90 \%-130 \%$ however, it may be rational for the government to be prepared to mitigate the effects of short-term losses of tax revenue, while enjoying the greater social cost savings. This, if implemented may possibly represent one of the greatest empirically estimated health economic benefits due to any single public health policy intervention in the Sri Lankan history.

\section{Conclusion}

Sri Lanka could move closer to its tobacco control targets by implementing the suggested fiscal policy, based on the above defined benchmarks. This can optimize the government tax revenue, significantly reduce social cost of tobacco consumption, shrink public spending for healthcare ailments associated with tobacco use and uplift the health-related quality of life of Sri Lankans. The tax rates must be adjusted annually to absorb the inflation and growth in income levels to continue the benefits of reduction in tobacco consumption. Since the calculations were based on 2019 prices of cigarettes, the model outputs need to be adjusted using the latest prices whenever the implementation decision is taken.

Given the transparent methodology and the overall positive outcome for the government and the public with minimal impact to industry existence, the suggested new fiscal limits may be acceptable in its scientific merits to all segments of the society including the tobacco industry.

\section{Ethical issues \\ Ethical clearance was not required as the article was an economic analysis} based on published literature.

\section{Competing interests}

Authors declare that they have no competing interests.

\section{Authors' contributions}

All authors contributed significantly, to the conception, design, analysis and interpretation of data, and the writing of the paper.

\section{Authors' affiliations}

${ }^{1}$ University of New South Wales, Sydney, NSW, Australia. ${ }^{2}$ University of Sydney, Sydney, NSW, Australia. ${ }^{3}$ Campbell Collaboration, New Delhi, India. ${ }^{4}$ National Institute of Medical Statistics, New Delhi, India. ${ }^{5}$ The University of Queensland, 


\section{Brisbane, QLD, Australia.}

\section{Supplementary files}

Supplementary file 1 contains the static Excel model used in the base case analysis.

\section{References}

1. World Health Organization (WHO). WHO global report: mortality attributable to tobacco. Geneva: WHO; 2015.

2. Rehm J, Taylor B, Room R. Global burden of disease from alcohol, illicit drugs and tobacco. Drug Alcohol Rev. 2006;25(6):503-513. doi:10.1080/09595230600944453

3. World Health Organization (WHO). Economic and social costs of tobacco and alcohol in Sri Lanka 2015. Colombo, Sri Lanka: National Authority on Tobacco and Alcohol; 2017.

4. Liang L, Chaloupka F, Nichter M, Clayton R. Prices, policies and youth smoking, May 2001. Addiction. 2003;98 Suppl 1:105-122. doi:10.1046/j.1360-0443.98.s1.7.x

5. Heckman BW, Cummings KM, Nahas GJ, et al. Behavioral economic purchase tasks to estimate demand for novel nicotine/tobacco products and prospectively predict future use: evidence from the Netherlands. Nicotine Tob Res. 2019;21(6):784-791. doi:10.1093/ ntr/nty042

6. World Health Organization (WHO). WHO report on the global tobacco epidemic 2015: raising taxes on tobacco. Geneva: WHO; 2015.

7. Jha P, Peto R. Global effects of smoking, of quitting, and of taxing tobacco. N Engl J Med. 2014;370(1):60-68. doi:10.1056/ NEJMra1308383

8. World Health Organization (WHO). WHO report on the global tobacco epidemic, 2013: enforcing bans on tobacco advertising, promotion and sponsorship. Geneva:WHO; 2013.

9. World Health Organization (WHO). WHO technical manual on tobacco tax administration. Geneva: WHO; 2010.

10. Gilmore AB, Tavakoly B, Taylor G, Reed H. Understanding tobacco industry pricing strategy and whether it undermines tobacco tax policy: the example of the UK cigarette market. Addiction. 2013;108(7):1317-1326. doi:10.1111/add.12159

11. Golden SD, Smith MH, Feighery EC, Roeseler A, Rogers T, Ribisl $\mathrm{KM}$. Beyond excise taxes: a systematic review of literature on nontax policy approaches to raising tobacco product prices. Tob Control. 2016;25(4):377-385. doi:10.1136/tobaccocontrol-2015-052294

12. Warner KE. Understanding the association between the $\mathrm{WHO}$ Framework Convention on Tobacco Control, adoption of tobacco control policies, and reduction in smoking prevalence. Lancet Public Health. 2017;2(4):e158-e159. doi:10.1016/s2468-2667(17)30052-x

13. Gravely S, Giovino GA, Craig L, et al. Implementation of key demandreduction measures of the WHO Framework Convention on Tobacco Control and change in smoking prevalence in 126 countries: an association study. Lancet Public Health. 2017;2(4):e166-e174. doi:10.1016/s2468-2667(17)30045-2

14. Yeh CY, Schafferer C, Lee JM, Ho LM, Hsieh CJ. The effects of a rise in cigarette price on cigarette consumption, tobacco taxation revenues, and of smoking-related deaths in $28 \mathrm{EU}$ countries-applying threshold regression modelling. BMC Public Health. 2017;17(1):676. doi:10.1186/s12889-017-4685-x

15. Ho LM, Schafferer C, Lee JM, Yeh CY, Hsieh CJ. The effect of cigarette price increases on cigarette consumption, tax revenue, and smoking-related death in Africa from 1999 to 2013. Int J Public Health. 2017;62(8):899-909. doi:10.1007/s00038-017-0980-7

16. Shang C, Chaloupka FJ, Fong GT, Gupta PC, Pednekar MS. The association between state value-added taxes and tobacco use in
India-Evidence from GATS and TCP India survey. Nicotine Tob Res. 2018;20(11):1344-1352. doi:10.1093/ntr/ntx184

17. Rodríguez-Iglesias G, Schoj V, Chaloupka F, Champagne B, González-Rozada M. Analysis of cigarette demand in Argentina: the impact of price changes on consumption and government revenues. Salud Publica Mex. 2017;59(1):95-101. doi:10.21149/7861

18. Ministry of Finance. Fiscal Management Report. Sri Lanka: Ministry of Finance; 2017.

19. Ceylon Tobacco Company. Annual Report. Sri Lanka: Ceylon Tobacco Company PLC; 2016.

20. Kostova D, Ross H, Blecher E, Markowitz S. Is youth smoking responsive to cigarette prices? evidence from low- and middleincome countries. Tob Control. 2011;20(6):419-424. doi:10.1136/ tc. 2010.038786

21. Mushtaq N, Mushtaq S, Beebe LA. Economics of tobacco control in Pakistan: estimating elasticities of cigarette demand. Tob Control. 2011;20(6):431-435. doi:10.1136/tc.2010.040048

22. Kostova D, Tesche J, Perucic AM, Yurekli A, Asma S. Exploring the relationship between cigarette prices and smoking among adults: a cross-country study of low- and middle-income nations. Nicotine Tob Res. 2014;16 Suppl 1:S10-15. doi:10.1093/ntr/ntt170

23. Krahn M, Gafni A. Discounting in the economic evaluation of health care interventions. Med Care. 1993;31(5):403-418. doi:10.1097/00005650-199305000-00003

24. Choi SE. Are lower income smokers more price sensitive?: the evidence from Korean cigarette tax increases. Tob Control. 2016;25(2):141-146. doi:10.1136/tobaccocontrol-2014-051680

25. Hu TW, Mao Z, Liu Y, de Beyer J, Ong M. Smoking, standard of living, and poverty in China. Tob Control. 2005;14(4):247-250. doi:10.1136/tc.2004.010777

26. Ross H, Stoklosa M, Krasovsky K. Economic and public health impact of 2007-2010 tobacco tax increases in Ukraine. Tob Control. 2012;21(4):429-435. doi:10.1136/tc.2010.040071

27. Alpert HR, Vardavas $\mathrm{Cl}$, Chaloupka FJ, et al. The recent and projected public health and economic benefits of cigarette taxation in Greece. Tob Control. 2014;23(5):452-454. doi:10.1136/ tobaccocontrol-2012-050857

28. Salti N, Chaaban J, Nakkash R, Alaouie H. The effect of taxation on tobacco consumption and public revenues in Lebanon. Tob Control. 2015;24(1):77-81. doi:10.1136/tobaccocontrol-2012-050703

29. Nargis N, Ruthbah UH, Hussain AK, Fong GT, Huq I, Ashiquzzaman SM. The price sensitivity of cigarette consumption in Bangladesh: evidence from the International Tobacco Control (ITC) Bangladesh Wave 1 (2009) and Wave 2 (2010) Surveys. Tob Control. 2014;23 Suppl 1:i39-47. doi:10.1136/tobaccocontrol-2012-050835

30. Nargis N, Fong GT, Chaloupka FJ, Li Q. The choice of discount brand cigarettes: a comparative analysis of International Tobacco Control surveys in Canada and the USA (2002-2005). Tob Control. 2014;23 Suppl 1:i86-96. doi:10.1136/tobaccocontrol-2012-050851

31. Forey B, Hamling J, Hamling J, Thornton A, Lee P. International Smoking Statistics. Sutton, United Kingdom: PN Lee Statistics \& Computing; 2013.

32. Jha P. Avoidable global cancer deaths and total deaths from smoking. Nat Rev Cancer. 2009;9(9):655-664. doi:10.1038/nrc2703

33. Hill C. Impact of Price Increases on Tobacco Consumption. Paris: Institut Gustave Roussy; 2013.

34. Van Walbeek C. Industry responses to the tobacco excise tax increases in South Africa. S Afr J Econ. 2006;74(1):110-122. doi:10.1111/j.1813-6982.2006.00051.x

35. Cornelsen L, Normand C. Is roll-your-own tobacco substitute for manufactured cigarettes: evidence from Ireland? J Public Health (Oxf). 2014;36(1):65-71. doi:10.1093/pubmed/fdt030 